\title{
PERANCANGAN ILUSTRASI WAYANG POTEHI UNTUK APLIKASI KE MEDIA PROMOSI
}

\author{
Anny Valentina ${ }^{1}$, Herwindo Tando ${ }^{2}$, Regina $^{3}$ \\ ${ }^{1}$ Jurusan Desain Komunikasi Visual, Fakultas Seni Rupa dan Desain Universitas Tarumanagara, Jakarta \\ Email: annyv@fsrd.untar.ac.id \\ ${ }^{2}$ Jurusan Desain Komunikasi Visual, Fakultas Seni Rupa dan Desain Universitas Tarumanagara, Jakarta \\ Email: euwin_tan76@yahoo.com \\ ${ }^{1}$ Jurusan Desain Komunikasi Visual, Fakultas Seni Rupa dan Desain Universitas Tarumanagara, Jakarta \\ Email: regina@fsrd.untar.ac.id
}

\begin{abstract}
ABSTRAK
Salah satu jenis wayang yang unik dan menarik adalah wayang milik orang Tionghoa yaitu yang kita kenal dengan Wayang Potehi. Wayang Potehi sendiri merupakan akulturasi budaya yang sangat bernilai untuk dijaga kelestariannya. Dewasa ini Wayang Potehi mengalami penurunan minat atau bahkan sudah dilupakan, terutama dari kalangan anak muda. Melalui kegiatan pengabdian kepada masyarakat yang bertujuan untuk meningkatkan kepedulian anak muda pada khususnya dan masyarakat pada umumnya tentang keberadaan Wayang Potehi. Melalui survei yang dilakukan sebagian besar responden (anak muda) jika ditanya tentang Wayang Potehi banyak diantara mereka yang tidak mengetahui. Salah satu hal yang bisa digunakan untuk membangkitkan ketertarikan generasi muda adalah melalui media yang mereka kenal dan sukai saat ini. Salah satunya adalah melalui membuat gambar ilustrasi karakter Wayang Potehi dengan gaya yang lebih dekat dengan anak muda sehingga kedepan bisa dibuatkan aplikasinya ke media promosi yang dekat dengan anak muda.
\end{abstract}

Kata kunci: Wayang Potehi, Gambar, Ilustrasi, Media Promosi

\section{PENDAHULUAN}

Salah satu warisan budaya Indonesia adalah Wayang. Wayang adalah seni pertunjukan boneka yang memiliki gaya tutur dan keunikan tersendiri. Wayang memiliki banyak jenis dan berbedabeda antara satu dengan jenis lainnya, seperti tokoh, cerita, bahan pembuatan wayang dan lainlainnya dilihat dari asal daerah wayang tersebut. Salah satu jenis wayang yang unik dan menarik adalah wayang milik orang Tionghoa yang kita kenal dengan Wayang Potehi. Dalam Kamus besar bahasa Tionghoa mengatakan bahwa Potehi (布袋戲) adalah boneka kayu dengan kantong kain, suatu jenis wayang golek. Boneka kayu Potehi (布袋戲) agak kecil, bagian kepala bersambung dengan kantong kain, di luarnya dikenakan pakaian panggung. Tangan seniman dimasukan ke dalam kantong untuk mengendalikan gerak boneka, maka dinamakan pula boneka tangan (Yuanzhi dalam Kuardhani, 2011: 16).

Menurut legenda, kesenian yang telah berumur sekitar 3000 tahun ini berasal dari sebuah penjara, dimana terdapat lima orang narapidana yang akan menerima hukuman mati, empat orang narapidana tersebut merasa sedih akan hukuman mati yang akan mereka terima, tetapi satu narapida lainnya tidak demikian, karena ia tahu bagaimanapun hukuman mati akan tetap mereka terima, oleh karena itu ia berusaha untuk bersenang-senang, dan salah satu idenya adalah dengan piring, panci, dan peralatan lainnya untuk memainkan wayang. Bunyi tabuhan dari mereka terdengar juga oleh Kaisar, yang kemudian mereka diminta untuk menghibur Kaisar dan akhirnya merekapun dibebaskan dari hukuman mati. Wayang Potehi awalnya digunakan sebagai fungsi sosial dan ritual, tetapi seiring dengan perkembangan jaman maka menjadi salah satu pertunjukkan hiburan. Pada awal-awal masuknya Wayang Potehi ke Indonesia lakon yang dibawakan kebanyakan masih asli dari negeri Cina. Tetapi dengan berjalannya waktu lakon yang 
dipentaskan pun mulai ke arah modern seperti cerita Sun Go Kong (Kera Sakti). Bahasa yang digunakan pun mulai bercampur dengan bahasa lokal seperti bahasa Jawa. Seperti pementasan wayang lainnya, Wayang Potehi juga memiliki alat musik pengiring dalam pementasan antara lain tambur, kendang, suling, kecer dan rebab.

Seni wayang ini pernah tenggelam sesaat setelah dikeluarkannya Instruksi Presiden Nomor 14 Tahun 1967, yang melarang pertunjukkan seni Cina. Wayang Potehi baru menggeliat kembali setelah dicabutnya inpres tersebut oleh Presiden Abdurrahman Wahid pada masa pemerintahannya (Kompas, Wayang Potehi, dari Cina ke Jawa ; 2007,17).

Kurangnya minat masyarakat yang tertarik terhadap wayang potehi, pertunjukan yang dulu dikenal berfungsi sebagai ritual, sekarang hanya dikenal sebagai pertunjukan boneka biasa. Meskipun kini pertunjukan wayang potehi sudah tidak hanya dilakukan di klenteng, namun juga dilakukan di mall, kampus, sekolah, gereja, pondok pesantren, galeri seni, museum, dan tempat hiburan lainnya, masih banyak masyarakat yang tidak mengetahui keberadaan tentang wayang potehi. (Kuardhani, 2011: 6) Wayang Potehi merupakan akulturasi budaya yang sangat bernilai untuk dijaga kelestariannya, sehingga diperlukan suatu perhatian khusus untuk melakukan revitalisasi agar menumbuhkan minat dan pengetahuan akan Wayang Potehi.

Gambar Ilustrasi dipilih sebagai media awal untuk meningkatkan minat masyarakat khususnya generasi muda. Ilustrasi berfungsi sebagai alat komunikasi dan juga berguna untuk merekam atau menjelaskan sebuah kejadian. Di masa kini, penggunaan ilustrasi sudah semakin luas yakni, untuk komunikasi, membujuk sasaran, memberikan informasi, edukasi dan juga sarana hiburan. Dalam perkembangannya ilustrasi secara lebih lanjut ternyata tidak hanya berguna sebagai sarana pendukung cerita, tetapi dapat juga menghiasi ruang kosong misalnya dalam majalah, Koran, tabloid, dan lainnya. Ilustrasi bisa berbentuk macam-macam, seperti karya seni sketsa, lukis, grafis, karikatural, dan akhir-akhir ini bahkan banyak dipakai image bitmap hingga karya foto. (Kusrianto, 2007:140)

\section{METODE PELAKSANAAN PKM}

Kepedulian lembaga pendidikan tinggi dalam rangka pelestarian dan revitalisasi warisan budaya merupakan salah satu kepedulian khususnya pada bidang ilmu Desain. Kegiatan Pengabdian Pada Masyarakat berupa pembuatan gambar ilustrasi ini merupakan kegiatan Pengabdian Pada Masyarakat yang berkelanjutan. Pada kegiatan kali ini menitikberatkan pada pembuatan sebuah gambar ilustrasi tokoh wayang potehi yang cukup dikenal.

Pelaksanaan kegiatan ini melibatkan staff pengajar dan mahasiswa yang memiliki kompetensi pada pembuatan gambar ilustrasi. Berikut adalah kerangka pelaksanaannya:

- Menemukan masalah

- Mencari data tentang Wayang Potehi yang dikenal

- Menemukan pandangan dan wawasan pada khalayak yang disasar

- Memberikan saran kreatif

- Mencari referensi

- Membuat gambar ilustrasi

- Menyiapkan alternatif

- Eksekusi ide kreatif dan Revisi

\section{PEMBAHASAN}

\section{Menemukan Masalah :}

Kurangnya minat masyarakat yang tertarik terhadap wayang potehi, pertunjukan yang dulu dikenal berfungsi sebagai ritual, sekarang hanya dikenal sebagai pertunjukan boneka biasa. 
Meskipun kini pertunjukan wayang potehi sudah tidak hanya dilakukan di klenteng, namun juga dilakukan di mall, kampus, sekolah, gereja, pondok pesantren, galeri seni, museum, dan tempat hiburan lainnya, masih banyak masyarakat yang tidak mengetahui keberadaan tentang wayang potehi. Hal ini juga dibuktikan dari hasil survey yang dilakukan bahwa $70 \%$ dari generasi milenial tidak mengenal wayang Potehi. Beberapa menjawab wayang potehi sebagai Topeng, Boneka keagaaman serta Patung dan beberapa dari mereka yang menjawab Wayang, tetapi tidak tahu jenis wayang apa. Kerena itulah PKM ini bertujuan untuk mengenalkan wayang Potehi kepada generasi milenial.

\section{Pengambilan data cerita wayang Potehi yang dikenal:}

Pertunjukan Wayang Potehi bukan sekadar pertunjukan hiburan tetapi memiliki makna filosofis, menunjukkan fungsi sosial, serta bagian dari ritual sakral. Melihat dari makna yang cukup dalam, selain berhubungan dengan manusia, juga memiliki arti sacral maka diambil gambar yang memiliki makna hubungan antar manusia, alam dan ke-Tuhanan (sakral).

Tema cerita Wayang Potehi biasanya dipengaruhi oleh tempat pementasan. Bila wayang dipentaskan di Klenteng, biasanya mengambil tema cerita asli Tiongkok, seperti Legenda Dinasti Tong, Dinasti Song, atau Dinasti Ming. Tetapi bila Wayang Potehi dipentaskan di hadapan penonton atau di luar Klenteng untuk acara hajatan atau acara lainnya, biasanya mengambil cerita yang lebih populer. Lakon yang dipilih memiliki makna tertentu bagi kehidupan penontonnya. Lakon Potehi yang dimainkan berorientasi seputar dunia kepahlawanan dan kehidupan. Lakon yang dimainkan sangat menggunggulkan kerja keras dan semangat yang tinggi dalam kehidupan. Melalui cerita dari lakon yang dipentaskan, diharapkan para penonton bias mengambil nilai kebaikan dalam oementasan tersebut, serta diterapkan dalam kehidupan mereka di dunia nyata.

Salah satu lakon yang sangat populer dalam pementasan Potehi adalah Xue Rengui (Si Jin Koei). Ringkasan cerita :

Lakon Xue Rengui Tjeng Tang merupakan sebuah foklor dari masyarakat Tiong Hoa. Cerita tokoh Xue Rengui Tjeng Tang sangat diminati oleh masyarakat pada umumnya, karena di dalamnya terkandung makna filosofis bagi kehidupan masyarakat Tiong Hoa. Xue Rengui adalah sebuah kisah Tiongkok klasik yang kini tak banyak dikenali lagi oleh masyarakat Tiong Hoa di Indonesia. Seperti halnya Sam Kok, Ouw Peh Coa, Song Kang, Sampek Engtay, dan See $\mathrm{Yu}$, lakon ini pernah terkenal pada abad XX-an. Tak hanya masyarakat Tiong Hoa, tetapi juga masyarakat Indonesia sendiri sekitar tahun 1950-an. Lakon ini merupakan kisah kepahlawanan, kewiraan, dan patriotisme serta keikhlasan membela negara. Sikap seperti ini sudah jarang kita temukan pada saat ini. Pertunjukan Wayang Potehi biasanya dilakukan dua kali dalam setahun dan itupun kita menikmatinya hanya didalam Kelenteng, tetapi dengan pergeseran fungsi dan makna dari lakon itu sendiri Wayang Potehi khususnya lakon Xue Rengui Tjeng Tang menjadi sebuah tontonan rakyat dan hiburan yang bisa dinikmati oleh siapapun. Pertunjukan ini adalah kisah Xue Rengui menggempur negeri timur atau Xue Rengui Tjeng Tang. Bermula dari mimpi Kaisar Lie Sie Bin, kaisar Dinasti Tang. Dalam mimpinya, ia diselamatkan oleh seorang pemuda berbaju putih yang memiliki senjata tombak cagak. Mimpi ini ia ceritakan kepada penasihatnya, Kunsu Djie Bok Kong. Penasihat Djie kemudian menerka pemuda dalam mimpi Raja itu adalah Xue Rengui. Raja begitu mempercayai ramalan itu hingga keinginannya untuk bertemu sangat menggebu. Suatu ketika Kaisar Lie Sie Bin mendapat ancaman dari Kerajaan Ko Lek Kok yang telah dikudeta oleh Jenderal Gay Souw Bun. Ko Lek Kok adalah daerah di bawah pemerintahan Dinasti Tang. Mereka menyatakan perang terhadap pemerintahan yang sah. Bendera perang dikibarkan. Lie Sie Bin segera mengutus Tio Siu Koei menjadi komandan perang sekaligus bertugas untuk mencari pahlawan dalam mimpi kaisar. Sungguh buruk watak Tio Siu Koei. Bersama Oet Tie Kiong dan keluarga, mereka bermaksud menyembunyikan identitas Xue Rengui jika muncul. Akan tetapi kebenaran akan selalu menang, akhirnya Xue Rengui berhasil 
ditemukan dan menjadi raja di negeri timur.

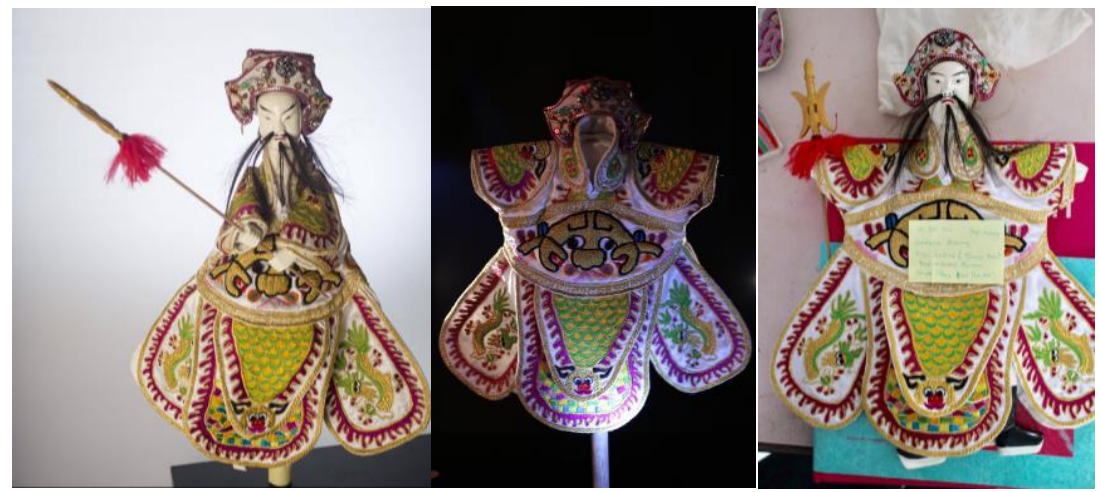

Gambar 1. Karakter

\section{Menemukan pandangan dan wawasan pada khalayak yang disasar :}

Image yang langsung bisa mereka rasakan dari melihat visual wayang potehi tersebut adalah : SERAM, MENAKUTKAN, ANEH. akan tetapi beberapa dari mereka juga menyatakan wayang potehi menarik.

\section{PERANCANGAN :}

\section{Keputusan Eksekusi Visual :}

Diputuskan untuk menggunakan ilustrasi dengan jenis Kartun karena melalui survei, didapatkan data bahwa generasi muda lebih memilih ilustrasi, walaupun tidak sedikit juga yang memilih foto. Diputuskan bergaya Kartun, karena bisa mengubah image seram dari wayang potehi. Untuk kedepannya akan juga dibuat dengan gaya realis.
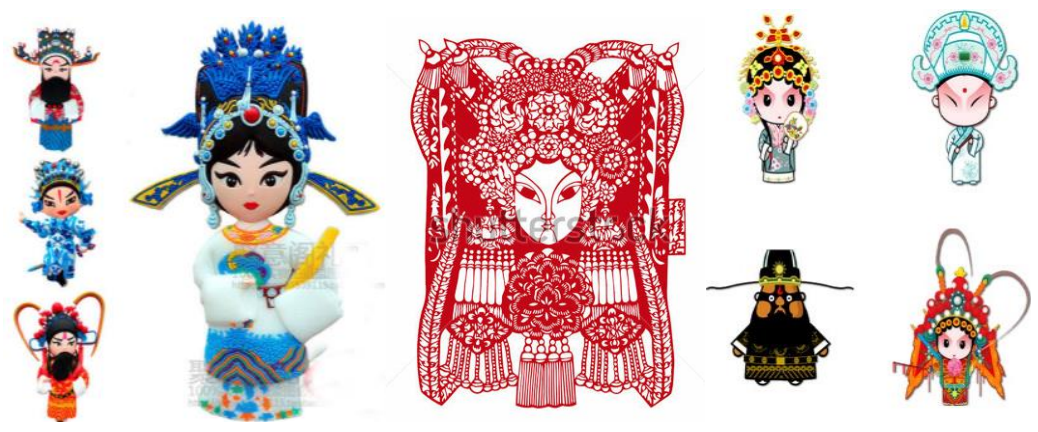

Gambar 2. Referensi Visual
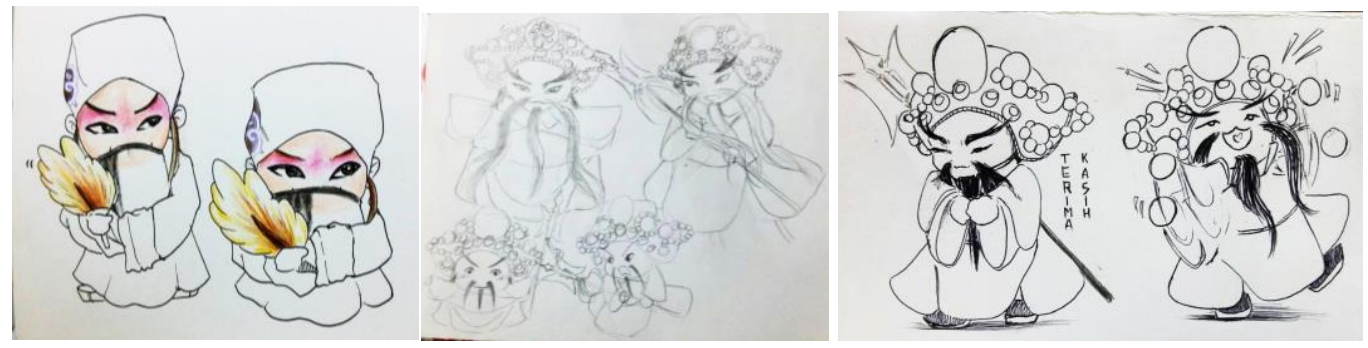

Gambar 3. Desain awal dan Revisi 


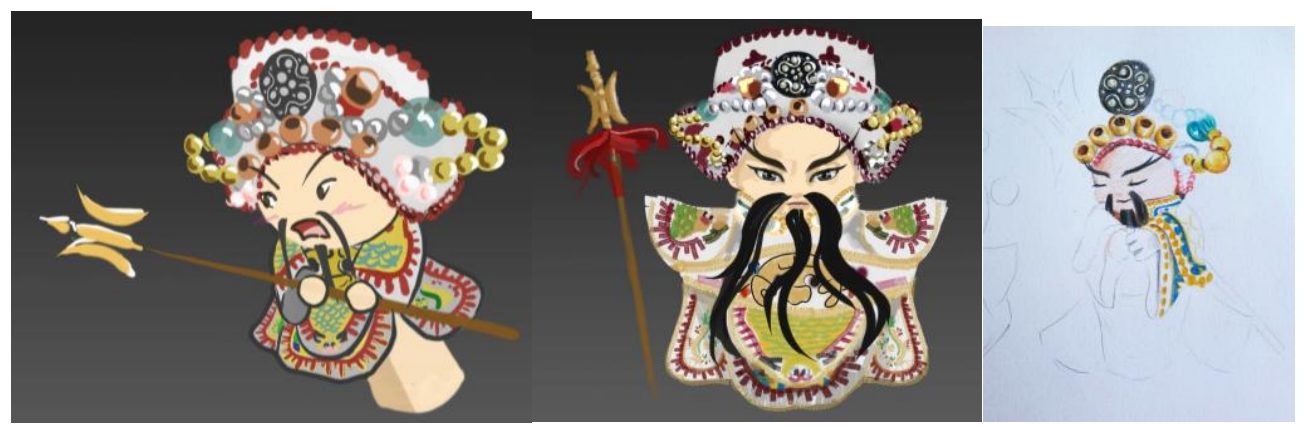

Gambar 4. Finalisasi
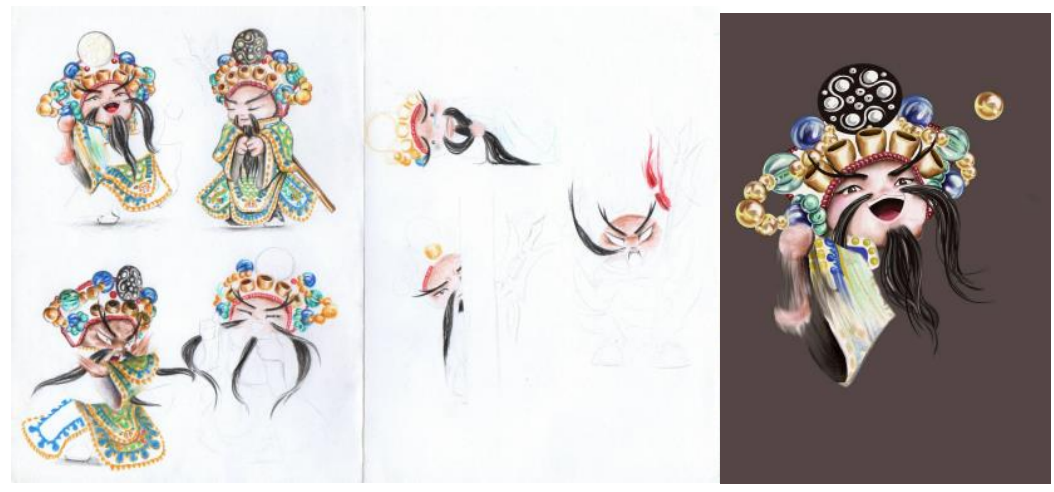

Gambar 5. Finalisasi (2)

\section{HASIL}
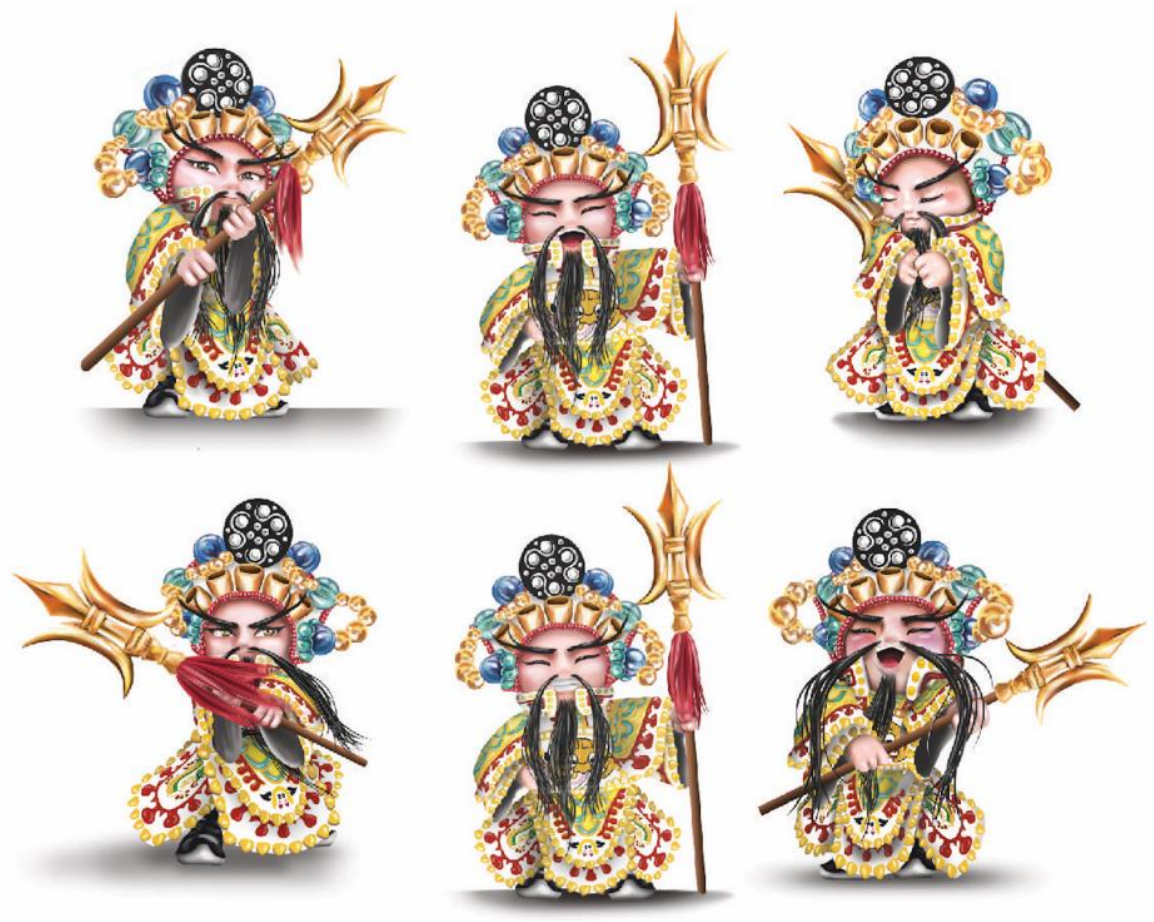

Gambar 6. Hasil 


\section{KESIMPULAN DAN SARAN}

Sebuah Kesenian hasil akulturasi budaya seperti wayang potehi sangat membutuhkan peran serta dan perhatian generasi penerusnya. Amat disayangkan budaya yang udah ratusan tahun ini sudah tersisihkan dan hampir punah. Melalui pembuatan gambar ilustrasi diharapkan mampu untuk memberikan sumbangan bagi komunitas wayang potehi, agar masyarakat bisa lebih mengenal dan mencintai budaya yang telah berumur ratusan tahun ini.

Untuk lebih memperkenalkan budaya seperti wayang potehi ini dibutuhkan perhatian lebih lagi, media yang menarik dan dekat dengan generasi muda sangat dibutuhkan untuk menarik minat, melalui gambar ilustrasi ini didapatkan respon positif dari generasi muda, mereka bisa menerima gambar ilustrasi ini dengan baik dan mampu menghapus kesan seram dari wayang potehi. Melihat mulai banyaknya kunjungan dari luar daerah ke paguyuban bahkan ada pula yang datang dari luar negeri, selanjutnya lustrasi ini akan diterapkan pada materi souvenir dan materi promosi lainnya.

\section{Ucapan Terima Kasih (Acknowledgement)}

Terima kasih kepada Direktur Penelitian dan Pengabdian kepada Masyarakat Universitas Tarumanagara yang telah memberikan kesempatan untuk melakukan pengabdian ini, juga kepada seluruh ketua dan staff di DPPM Untar yang telah membatu dan mendukung, kepada Panitia Senapenmas Universitas Tarumanagara.

Bapak Toni Harsono yang telah memberikan kesempatan, informasi serta bantuan selama proses pengambilan data dan gambar.

Rekan-rekan Dalang dan seluruh anggota paguyuban wayang potehi Gudo

\section{REFERENSI}

\section{Buku}

Adriana, Leoidra. 2003. Wayang Potehi: Identitas dan Fungsi

Amir, Hazim. 1994. Nilai-nilai Etis dalam Wayang. Jakarta: Sinar Harapan.

Kong, Yuanzhi. 1999, ZhongguoYindunixiyaWenhuaJiaoliu. Beijing: Beijing DaxueChubanshe

Kuardhani, Hirman. 2011, Toni Harsono Maecenas Potehi dari Gudo, Yensen Project

Kuardhani, Hirman. 2012, Mengenal wayang Potehi di Jawa, Yensen Project

Mulyono, Sri. 1989. Wayang, Asal-usul, Filsafat, dan Masa Depannya. Jakarta: CV Haji Masagung.

Soekatno. (1989). Wayang Kulit Purwa: Klasifikasi Jenis dan Sejarah. Semarang: Aneka Ilmu, 1

\section{Artikel}

"Perlu Inovasi Untuk Mempopulerkan Wayang Potehi," Kompas. 23 Mei 2005, 10.

Anugrah, Ch Dwi. “Wayang Potehi, Perekat Kebersamaan,” Kompas, 19 Jan. 2009, 4.

“Wayang Potehi, Dari China Ke Jawa,” Kompas, 11 Feb. 2007, 17.

\section{Internet}

http://www.coverstory-lingkarberita.com/2012/01/imlek-dan-wayang-potehi-pas.html 